\section{'ORAL HEALTH CRISIS' LOOMS FOR BRITISH PUBLIC}

Professor Phil Taylor, Dean-Elect of the Royal College of Surgeons of Edinburgh (RCSEd)'s Faculty of Dental Surgery, expressed concern over the long-term oral

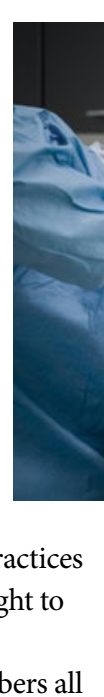
re-open. over the UK, says that while many dental practices are now seeing patients again, there is still a great deal of worry within the profession around the aftereffects of closures over recent months.

Professor Taylor said: 'We are now one month on from dental practices in England being allowed to re-open to treat nonemergency patients after the pandemic forced the vast majority of practices to close their doors.

'While it's fantastic that many practices are now back up and running, there are still significant hurdles to overcome. Dentists are operating at a much lower capacity than preCOVID due to stringent cleaning measures in between patients, and we know from a survey of our members that only half of those that are open feel they can provide the full range of fillings and hygiene appointments.

'Of course this improved protection is absolutely necessary in order to keep patients safe, but it does mean it will be a long time until dentists can effectively work through the backlog of patients which built up during the peak of the pandemic.

'There's still a lot of work to be done in
RCSEd, which represents members all

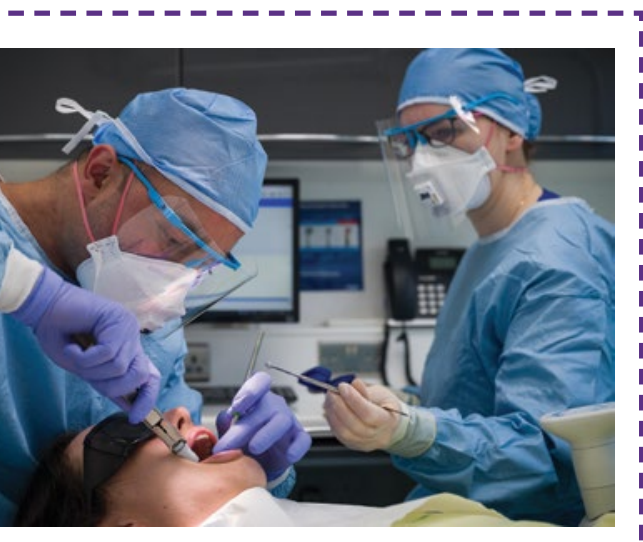

convincing patients that it is safe to go to their dental practice for routine check-ups. Many may not feel comfortable in doing so for some time, but we want to emphasise that it shouldn't be avoided and is perfectly safe to do so. Unfortunately, some of those who do try to get an appointment may be unable to, due to practices' vastly reduced capacity.'

RCSEd's Faculty of Dental Surgery recently carried out a survey of its members, which showed that half of dentists believe they have patients who have suffered permanent harm as a result of practice closures, and $87 \%$ feel there is a backlog which will cause further long-term deterioration.

Professor Taylor continued: 'We could find ourselves in a situation where oral health in the UK is severely impacted for years to come. The concern is that with this long-term disruption caused by coronavirus, we will begin to see patients not being able to access regular and essential dental care which will inevitably lead to undiagnosed dental disease and particularly oral cancer.

'Since Dental Health Surveys were established in 1968, we've seen a considerable improvement in the nation's dental health. We do not want to reverse the trend and come to a place where dentures and missing teeth are the norm once again.

\section{FDS WELCOMES INCLUSION OF ORAL HEALTH IN EARLY YEARS CURRICULUM}

The Faculty of Dental Surgery (FDS) at the Royal College of Surgeons of England has welcomed the Government's commitment to include oral health education in its reforms to the early years foundation stage (EYFS) statutory framework.

The FDS submitted evidence to the Department for Education earlier this year, calling for a requirement on promoting good oral health to be included as part of its Safeguarding and Welfare reforms.

Child tooth decay represents a major public health issue which has a significant impact on young children's overall health and wellbeing. This in turn leads to difficulty in concentrating and so affects their education. They can experience bullying as a result of the appearance of their teeth, as well as being at an increased risk of disease in their adult teeth. Tooth decay is also the leading cause of hospital admissions amongst five to nine year olds by some distance - there were 25,702 such admissions in 2018-19.

In its evidence, the FDS also repeated its calls for supervised tooth brushing in schools as there is significant evidence, notably from Scotland and Wales, that such initiatives are effective in improving children's oral health. However, the government state that individual settings and schools will be able to determine how the requirement to promote good oral health is met. Last year's Prevention Green Paper announced that the Government will consult on extending the provision of supervised tooth brushing programmes in England.

Mr Matthew Garrett, Dean of the FDS said: 'This new requirement to promote good oral health is fantastic news for children across England. While we would have liked to see supervised tooth brushing schemes mandated, this is a good first step in improving children's oral health.

'During the pandemic, dental services have rightly functioned differently to take the pressure off the NHS and save lives. This has meant that routine check-ups - where dental problems are often first spotted - have been paused, making this commitment to oral health in education settings more important than ever.' 